\title{
Medical management and leadership: a time of transition?
}

Helen Dickinson

University of New South Wales

Ringgold standard institution - Centre for Public Service Research

Campbell Canberra, Sydney, New South Wales 2052

Australia

Email: h.dickinson@adfa.edu.au

Grant Phelps

Ballarat Health Services - Internal Medicine

Drummond St , Ballarat, Victoria 3350

Australia

Erwin Loh

Monash Health Ringgold standard institution - Medical Administration

Clayton, Victoria

Australia

Marie Bismark

University of Melbourne

Melbourne,

Victoria

Australia

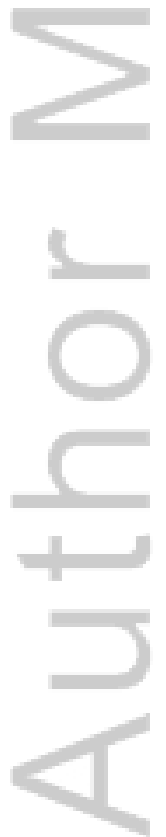

This is the author manuscript accepted for publication and has undergone full peer review but has not been through the copyediting, typesetting, pagination and proofreading process, which may lead to differences between this version and the Version of Record. Please cite this article as doi: 10.1111/imj.13479

This article is protected by copyright. All rights reserved. 
Perspectives on medical management and leadership are in a time of transition, but there is much we still need to better understand. This piece explores some of the tensions and dilemmas inherent in understandings of medical management and leadership.

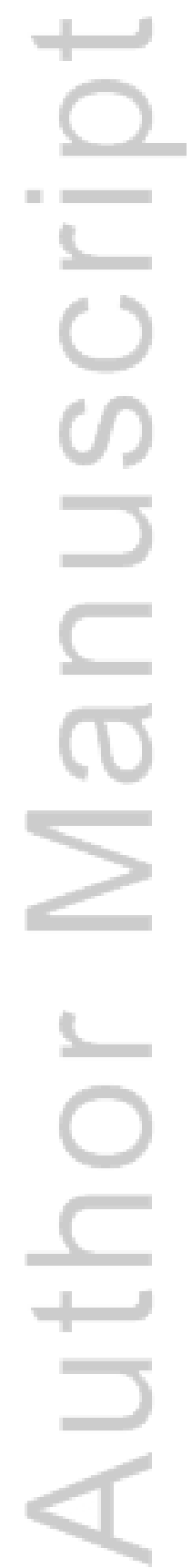

This article is protected by copyright. All rights reserved. 


\section{Medical management and leadership: a time of transition?}

Engaging doctors in formal leadership roles is frequently discussed as a way to drive improvement and higher quality care within health organisations (1). Yet many doctors have been reluctant to assume management and leadership roles, despite increasing evidence of benefit to the system when they do so. Management and leadership roles are often perceived as challenging and time-consuming and may result in doctors becoming isolated from their peer group as they 'go over to the dark side' (2). Doctors who have entered these roles have traditionally done so without substantive leadership experience or management training. However, these patterns and perspectives seem gradually to be shifting under the influence of various social, professional, educational, and demographic pressures. We believe that medical management and leadership is at a point of transition and looks set to shift from being the preserve of dedicated and enthusiastic individuals to being an established and legitimate component of the Australian health system as it continues to evolve as a world-class health system.

Evidence of this shift can be observed in the formalisation of medical management and leadership roles. The importance of involving doctors in the management and leadership of healthcare organisations has long been recognised by the profession and policymakers (3) and over time this has been achieved through a variety of different mechanisms (4). In recent years many health systems have created more formal roles for medical managers and leaders within organizations. What is interesting about these roles is they are more explicitly dedicated to management and leadership than traditional hybrid roles where doctors combined clinical practice alongside management and leadership responsibilities. An increasing number of doctors are 
transitioning out of clinical practice so that they can focus on organisational processes (5). However, it is worth noting that full-time medical executive roles and part-time clinician manager/medical director roles are not mutually exclusive and successful organisations typically provide a range of models of medical leadership.

With increasingly formalised roles, primarily dedicated to leadership and management, we also find that expectations about education and training are changing. Traditionally, a lack of competition - and perhaps a lack of organizational and professional understanding of medical leadership and management - has meant that doctors have not needed to be firmly versed in the detail of leadership and management theory and practice in order to assume these roles. Today, not only do we find that leadership and management appear as topic areas in university medical education, but doctors are also seeking out further study through Masters level qualifications in administration, public health, policy and management areas (6). Alongside these opportunities for formal post-graduate study, many individual health organisations now also offer their own in-house programs for upcoming medical managers and leaders.

So far we have mostly dealt with issues that relate to the demand side of medical leadership and management, but we are also seeing changes to supply-side factors: as a result of greater competition for specialty training, an increased understanding of health systems thinking, and changes in the nature of work.

Medical management and leadership roles have traditionally been poorly regarded amongst the majority of doctors, often attracting little competition. There are signs of increasing competition for these roles today and this trend 
looks set to intensify in the coming years. The Australian medical workforce is currently undergoing significant changes with an oversupply of medical graduates alongside increasing numbers of international entrants (7). What this means is that some doctors may not end up in the career pathway of their choosing (8).

Australia uniquely benefits from a medical specialty college - The Royal Australasian College of Medical Administrators (RACMA) - that offers a Fellowship training program for those interested in becoming specialist medical administrators. Using RACMA figures on the extent of unmet demand for specialist medical administrators and clinical managers with RACMA associate fellowship, we find there is an undersupply of specialist medical administrators in the current health system (9). Given that there is an undersupply of medical administrators and demand for specialty training intensifies, it may be that we see greater demand for Clinicians with specialist management qualifications such as the RACMA fellowship.

While some doctors may be prompted to consider a career in medical management as a result of over-supply in other specialties, others will be pulled towards leadership and management roles by the opportunity to improve the health of many more patients by working at an organisational or system-wide level. Younger doctors who have been trained in health systems thinking at medical school, and who see opportunities for training in medical administration, may be more likely to view leadership and management roles as a legitimate career pathway. (10). As a result, we may see a transition in the age profile of individuals going into management and leadership roles with more young doctors choosing these roles as a promising career pathway in their own right.

This article is protected by copyright. All rights reserved. 
Another factor drawing doctors to management and leadership relates to the changing nature of work. Across the board people are living for longer and we are starting to see an elongation of our working lives (11). These demographic changes may make leadership and management roles more attractive to some doctors, either as a rewarding alternative to the physical demands of handson clinical care, or as a new challenge once they have reached the pinnacle of clinical practice. In addition, the medical workforce has moved from being dominated by men to having an equal share of male and female graduates (12) - many of whom may wish to combine a career with parenting or other social roles. Already we have seen the expansion of part-time clinical roles as more doctors seek to combine different roles in different settings across their professional and personal lives. Compared with specialties such as surgery, medical administration and leadership attracts more female trainees, though there is still a worrying gender imbalance at the highest levels of medical leadership. Health Workforce Australia (9) estimates that there are more than twice as many male medical administrators (112) as female (53) (pg. 358).

Together the forces described above are coalescing to drive medical leadership and management in new directions. But still, there is much that remains unclear. We do not have a shared view across the health system of what medical engagement in management and leadership should look like or what it should achieve. This uncertainty stands in contrast to more sophisticated understandings of health leadership in management within other health systems (e.g. UK, Denmark) and means that we lack a shared sense of job design, career pathway, professional development and many other important issues all of which have implications for the efficacy of these roles (5). We also lack a clear strategy for addressing the lack of diversity within the highest levels of medical leadership and management, despite 
compelling evidence that improved diversity benefits organisational performance.

As the Australian health system transitions to being one that accepts the legitimacy and credibility of medical management and leadership roles there is a need for a national debate over these issues. Without clear understandings of what these roles look like, how they should operate within the system, how we train, develop and recruit individuals for these roles and the role of different organisations and institutions in supporting them it is unlikely that we will be able to harness the full value of these roles.

This article is protected by copyright. All rights reserved. 


\section{References}

1. Conry MC, Humphries N, Morgan K, McGovan I, Montgomery A, Vedhara $\mathrm{K}$, et al. A ten year (2000-2010) stystematic review of interventions to improve quality of care in hospitals. BMC Health Services Research. 2012;12(275):1-16. 2. Spurgeon P, Clark J, Ham C. Medical leadership: from the dark side to centre stage. London: Radcliffe Publishing Limited; 20112011.

3. Berwick D. Eleven worthy aims of clinical leadership of health system reform. Journal of American Medical Association. 1994;272:797-802.

4. Dickinson H, Bismark MM, Phelps G, Loh E. Future of Medical Engagement. Australian Health Review. 2015.

5. Dickinson H, Bismark MM, Phelps G, Loh E, Morris J, Thomas L. Engaging professional in organisational governance: The case of doctors and their role in the leadership and management of health services. Melbourne: Melbourne School of Government, 2015.

6. Loh E. How and why medically-trained managers undertake postgraduate management training. Journal of Health Organization and Management. 2015;29(4):438.

7. Scott A, Joyce CM. The future of medical careers. Medical Journal of Australia. 2014;21 July:82-3.

8. Keva D, Lander FJ. Emerging inequality and potential unconstitutionality the case for reform of the intern priority system. Medical Journal of Australia. 2013;198:334-7.

9. Health Workforce Australia. Health workforce 2025: Doctors, nurses and midwives - volume 1. Adelaide: Health Workforce Australia, 2012.

10. The Royal Australasian College of Medical Administrators. Registrar Training Program Network Available from http://racma.edu.au/index.php?option=com content\&view=article\&id=523:regi strar-training-program-network\&catid=90:latest-news Accessed 18th September 20152015.

11. Dickinson H, Sullivan H. Imagining the 21st century public service workforce. Melbourne: School of Government, University of Melbourne, 2014. 12. Bismark MM, Morris J, Thomas L, Loh E, Phelps G, Dickinson H. Women in medical leadership: a qualitative study. BMJ Open. forthcoming.

This article is protected by copyright. All rights reserved. 


\section{University Library}

\section{- M M I E R R A A gateway to Melbourne's research publications}

Minerva Access is the Institutional Repository of The University of Melbourne

Author/s:

Dickinson, H;Phelps, G;Loh, E;Bismark, M

Title:

Medical management and leadership: a time of transition?

Date:

2017-07-01

Citation:

Dickinson, H., Phelps, G., Loh, E. \& Bismark, M. (2017). Medical management and leadership: a time of transition?. INTERNAL MEDICINE JOURNAL, 47 (7), pp.818-820. https://doi.org/10.1111/imj.13479.

Persistent Link:

http://hdl.handle.net/11343/293129 